\title{
TDMA based Approach on MAC Layer for IEEE Wireless LAN Standards
}

\author{
Tazeem Ahmad Khan \\ Research Scholar, \\ Department of ECE, JMI, New \\ Delhi 110025, India
}

\author{
Mirza Tariq Beg \\ Head, E \& C Deptt. \\ F/o Engg. \& Tech., JMI \\ New Delhi 110025, India
}

\author{
Mumtaz A. Khan \\ Head, Electrical Engg. Section, \\ F/o Engg \& Tech.,JMI \\ New Delhi 110025, India
}

\begin{abstract}
MAC layer is key of wireless network. TDMA approach is based on Maximum utilization of frequency spectrum. Packet error is also depending on frequency spectrum. The demands of WLAN Devices day by day increases exponentially and it operates in the specific narrow spectrum of frequency bands and also increase communication parameters programmed and control over Most modern wireless devices. In this paper, simulate and analyze the performance of existing MAC layer protocol and hybrid MAC with TDMA protocol in wireless local Area Network is presented. In this simulation, we present a MAC protocol based on IEEE 802.11g standard in the DCF mode and DCF with TDMA mode which is useful to improve packet collision in traditional wireless networks. In this analysis, improved performance with TDMA base MAC layer is compared without TDMA. We used simulation through using NS-2 Simulator.
\end{abstract}

\section{General Terms}

MAC layer, WLAN, Network, Simulation

\section{Keywords}

Distributed Coordinator Function (DCF), Medium access Control (MAC), Time Division Multiplexing Technique (TDMA).

\section{INTRODUCTION}

The wireless networks build up in infrastructure base or adhoc network. In a wireless network Medium Access Control (MAC) is a significant factor. With the help of MAC layer translate raw physical facility into usable network facility, so the option of a MAC protocol significantly impacts on the performance [4]. In a narrow specific spectrum utilized different access technique FDMA, CDMA and TDMA, In TDMA technique time is divided into the number of time slots frames with flat length. A pre-assigned time slots nodes can be transmit. Through this method, interference from neighboring nodes is reduced. So that TDMA protocols is advantageous in performance as compare among arbitrary MAC protocols access. For the reason of that dedicated time slots for each nodes pre-determined. In this simulation analysis we observe how to improve the performance existing MAC layer protocol and hybrid MAC with TDMA protocol in wireless local Area Network by proposing a above technique based on Binary Exponential Back off Algorithm (BEBA) [5].

\section{OVERVIEW OF WLAN MAC}

\subsection{MAC Layer Protocol}

MAC layer base on Contention free and Contention oriented access. Contention free is a distributed channel access mechanism based on Carrier Sense Multiple Access with
Collision Avoidance (CSMA/CA). CSMA/CA channel contention mechanism can also used with Request to send / Clear to Send (RTS/CTS) mechanism. The hidden node problem solved using RTS/CTS operation. DCF is used different frame space DIFS, IFS, SIFS for transmission a frame. Time space depends on the channel condition (idle or busy). If the channel is busy, it enters a backoff procedure among contention window $[7,10,11,12]$.

In case of distributed mechanism channel utilization is not sufficient, due to this throughput is limited [7, 11, 12].

\subsection{IEEE 802.11}

IEEE had been finalized Large number of networks Standards for PAN, LAN,MAN WAN, wireless LAN etc. Wireless LAN is also set of standards for implementing in the different frequency spectrum $2.4 \mathrm{G}, 3.6 \mathrm{G}$ and $5 \mathrm{GHz}$ bands. Standard committee IEEE is maintained WLAN standers. The WLAN family $(802.11, a, b, c, g, \ldots . . .$.$) has different modulation and$ different technique as per series of IEEE standards with same basic protocol. The $802.11 \mathrm{~b}$ protocol is accepted, which is original standard. Amendments, but this was a first widely accepted, IEEE $802.11 \mathrm{~g}$ followed by IEEE $802.11 \mathrm{~b}$. It works with OFDM modulation technique at Maximum data rate 54 Mbps or about $22 \mathrm{Mbps}$ average throughput. 802.11g Design with $802.11 \mathrm{~b}$ fully hardware backwards compatible [3,10].

Improve the efficiency of MAC layer Protocol, various new feature introduced with basic foundation of standards [7, 10]

\subsection{TDMA}

In today's hot research area to implements hybrid access technique Medium access control with Time division access technique. In these techniques improve the performance of wireless networks throughputs, end to end delay, minimization collision, energy efficient, high vehicle speed mobility and long distance [ $3,4,10,14,15,16,17]$. In this technique medium shared (Channel uses several time slots), PHY level and MAC layer level. Same transmission medium to allocate several stations contribute to only a fraction of its channel capacity.

The most important task in scheme a TDMA schedule is to allot time slots depending on the topology and workstation frame generation rates. Minimize to collisions avoidance and latency of every receiver workstation to design appropriate schedule $[10,13,18]$.

TDMA slot time Schedule avoided conflict to same node transmits \& receives a same time [5, 13]. In TDMA analysis reduces the collision effects and improvement in BW utilization \& collision reduction. 


\section{MOTIVATION}

Our simulation is based on open source simulator on Linux. TDMA model is simulating using open source simulator (NS2). NS-2 makes available significant support for simulation of OSI and TCP/IP model protocols. We investigated a performance evaluation to compare the loss rate and packet dropped. Binary Exponential Backoff Algorithm (BEBA) is executing which regulate the $\mathrm{CW}$ size dynamically in reply to collision probability. Embedded an algorithm in the IEEE 802.11g DCF. TDMA technique by allocated a unique time slots for every station.

\section{SIMULATIONS EXPLANATION}

In this Simulation we present 16-node structure show in Fig. 1 Ad-hoc Wireless Network simulation model. In this simulation model consist of 8 source node and 8 receiving nodes. We study 2 scenarios configured using the NS-2. The WLAN 802.11, G-standard scenario with and without TDMA. We observed the performance of the control packets in terms of data throughput and loss rates.

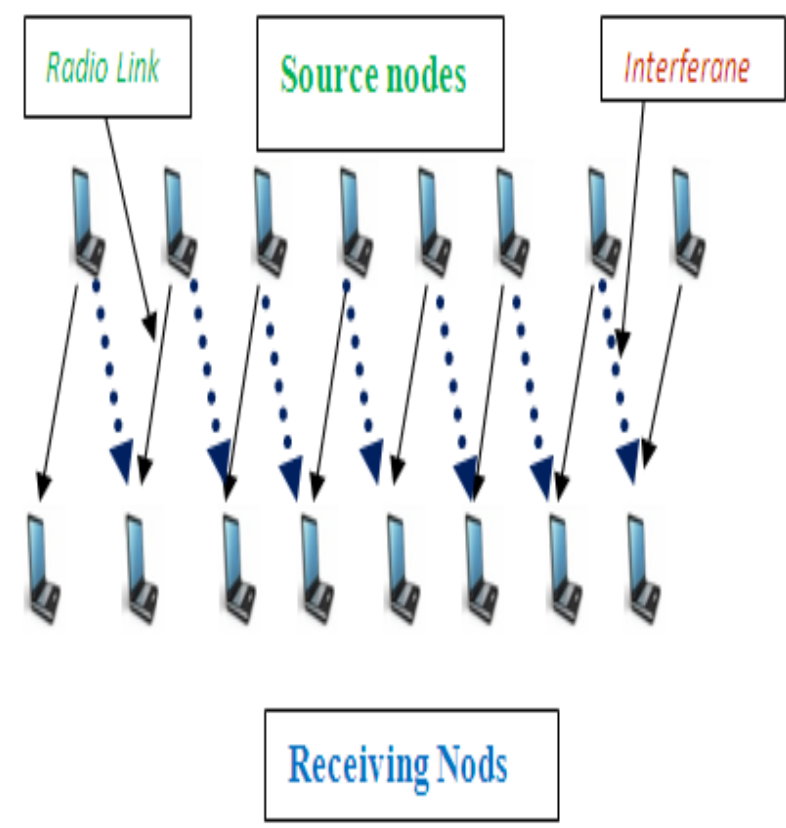

Fig. 1 Simulation Model: Ad-hoc WLAN

\subsection{Simulations Settings}

We generated the traffic of Different packet size based on CBR generator within the application layer, and a time interval of $0.008 \mathrm{~s}$

Table 1 shows the MAC layer parameters values used in the simulation.

Table 1. MAC Layer Parameter

\begin{tabular}{|c|c|}
\hline Parameter & Value \\
\hline Slot time_ & 9us \\
\hline CCA time_ & 3us \\
\hline SIFS_ & 16us \\
\hline
\end{tabular}

\begin{tabular}{|c|c|}
\hline DIFS_ & 28us \\
\hline Preamble Length__ & 96 bits \\
\hline PLCP Header Length__ & 40 bits \\
\hline PLCP Data Rate__ & 6 Mbps \\
\hline Max Propagation Delay__ & $5 \mathrm{us}$ \\
\hline Short Retry Limit__ & 7 \\
\hline Long Retry Limit_ & 4 \\
\hline Header Duration__ & $40 \mathrm{us}$ \\
\hline Symbol Duration_- & $8 \mathrm{us}$ \\
\hline RTS Threshold_ & 2346 \\
\hline CW Min__ & 15 \\
\hline CW Max_ & 1023 \\
\hline Rx Tx Turnaround Time__ & $2 \mathrm{us}$ \\
\hline
\end{tabular}

\subsection{Performance Evaluation}

As per our design simulation model $0,2,4,6 \ldots \ldots .14$ are source nodes and $1,3,5 \ldots 15$ receiving nodes. The application CBR source is different packet size. Our simulation model an Ad-hoc Network, we intended to better performance improve through puts and minimization loss data. These all are limited by size of network and link capacity.

In this simulation application layer CBR packets forward to lower layer UDP, UDP forward packets to MAC layer. MAC layer protocol work with or without TDMA to send the packet physical layer and NULL detector at receiver end. NS-2 simulator work with discrete time simulation, our simulation discrete time $.0625 \mathrm{sec}$ and total time $20 \mathrm{sec}$. Simulation parameters records in the form of receive bytes, received packet, loss packets during discrete time and find the performance as throughputs and loss data rate as following:

$$
\begin{aligned}
& \text { Average throughputs } \\
& =\frac{\text { total bytes received } * 8}{\text { Simulation Stop time }- \text { simulation start time }} \\
& \text { Average loss rate } \\
& =\frac{\text { total bytes loss } * 8}{\text { Simulation Stop time }- \text { simulation start time }}
\end{aligned}
$$

In MAC layer Protocol with TDMA technique by allocated a unique time slots for every station. Fig. 2 show TDMA nodes time slots Structure. Time slots time depends upon the no of nodes in the ad-hoc Network, our simulation time slots time is $.0625 \mathrm{sec}$. 


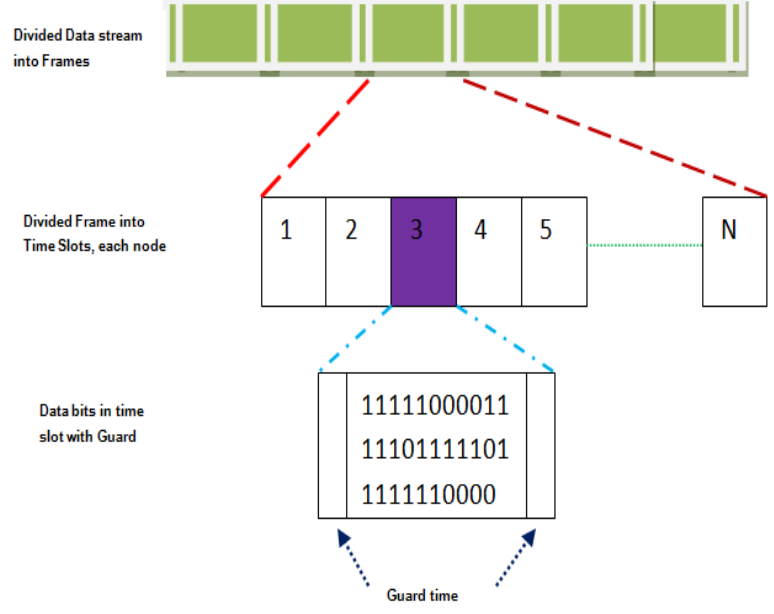

Fig. 2 TDMA nodes time slots Structure

In this simulation, we are performance analysis using different packet size. Our simulation has 6 different packet size from 128 bytes, 256 bytes, 512 bytes, 1024 bytes and 2048 bytes. The simulation results are shown in Table and graphs. We are four different scenario 802.11, 802.11g, TDMA + 802.11 and TDMA $+802.11 \mathrm{~g}$. The comparative results of four scenarios using different packets size are show in table 2 and table 3 in respect average receive data $\&$ average loss data rate.

Analysis different scenarios are show in Fig. 3 and Fig 4 for average receives data Rate and loss data rate respectively. From fig 3 TDMA based approach receive data is improve the performance as compare to without TDMA for larger packet size. Similarly form fig. 4 minimized loss data in TDMA approach as compare to without TDMA.

Table2. Average Receive Data Rate (Kbps) from Different Scenarios and Different Packet size

\begin{tabular}{|c|c|c|c|c|c|}
\hline \multicolumn{6}{|c|}{ Average Receive Data Rate (Kbps) } \\
\hline \multirow[b]{2}{*}{ Scenarios } & \multicolumn{5}{|c|}{ Packet Size } \\
\hline & $\begin{array}{c}2048 \\
\text { bytes }\end{array}$ & $\begin{array}{l}1024_{-} \\
\text {bytes }\end{array}$ & $\begin{array}{c}\text { 512_b } \\
\text { ytes }\end{array}$ & $\begin{array}{c}\text { 256_b } \\
\text { ytes }\end{array}$ & $\begin{array}{c}128 \_b \\
\text { ytes }\end{array}$ \\
\hline 802.11 & $\begin{array}{c}85.241 \\
4\end{array}$ & $\begin{array}{c}98.149 \\
4\end{array}$ & $\begin{array}{c}88.39 \\
18\end{array}$ & 69.69 & $\begin{array}{c}45.18 \\
44\end{array}$ \\
\hline $802.11 \mathrm{~g}$ & $\begin{array}{c}473.36 \\
5\end{array}$ & $\begin{array}{c}491.72 \\
76\end{array}$ & $\begin{array}{c}509.0 \\
442\end{array}$ & $\begin{array}{c}511.4 \\
694\end{array}$ & $\begin{array}{c}388.4 \\
704\end{array}$ \\
\hline $\begin{array}{c}\text { TDMA+8 } \\
02.11\end{array}$ & $\begin{array}{c}599.92 \\
32\end{array}$ & $\begin{array}{c}564.34 \\
56\end{array}$ & $\begin{array}{c}548.3 \\
856\end{array}$ & $\begin{array}{c}489.6 \\
24\end{array}$ & $\begin{array}{c}333.3 \\
552\end{array}$ \\
\hline $\begin{array}{c}\text { TDMA+8 } \\
02.11 \mathrm{~g}\end{array}$ & $\begin{array}{c}586.02 \\
4\end{array}$ & $\begin{array}{c}565.19 \\
68\end{array}$ & $\begin{array}{c}549.4 \\
496\end{array}$ & $\begin{array}{c}560.3 \\
904\end{array}$ & $\begin{array}{c}554.2 \\
304\end{array}$ \\
\hline
\end{tabular}

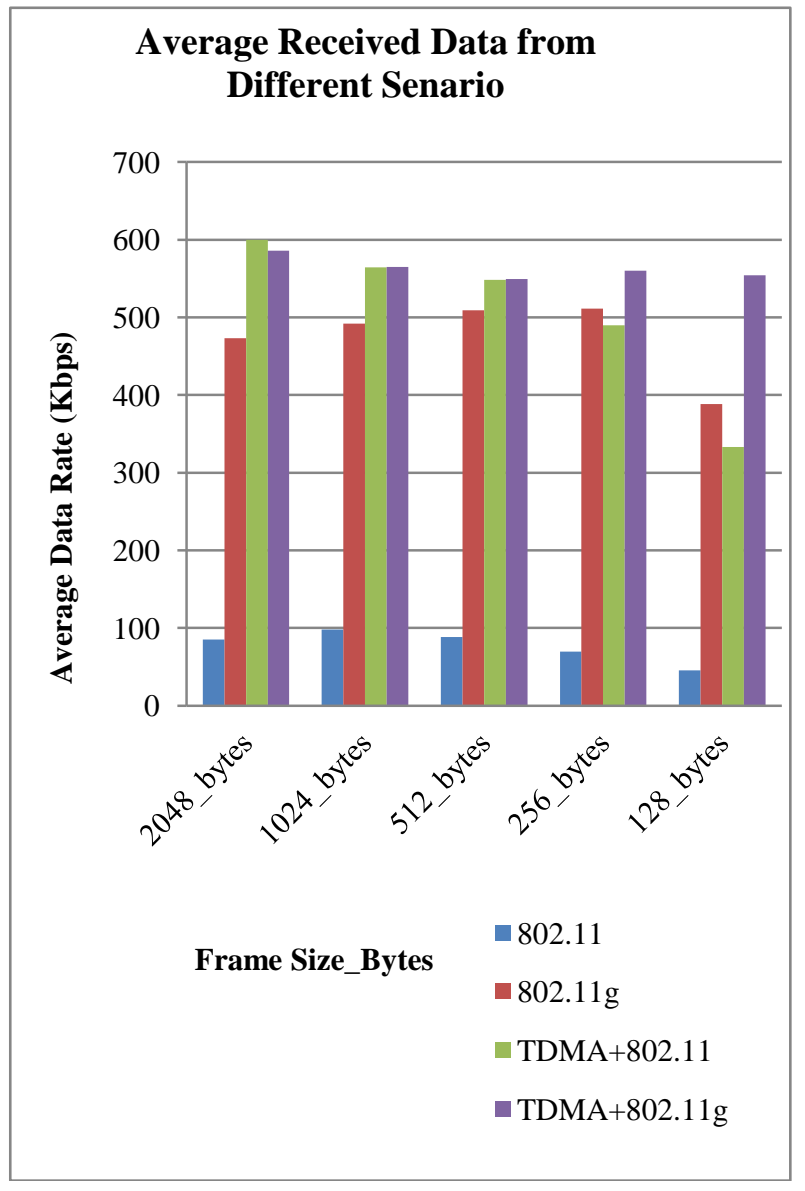

Fig. 3 Performance of average receive data rate vs. Packet size for Different scenario

Table3. Average Loss Data Rate (Kbps) from Different Scenarios and different Packet size

\begin{tabular}{|c|c|c|c|c|c|}
\hline \multicolumn{5}{|c|}{ Average Loss Data Rate (bps) } \\
\hline \multirow{2}{*}{ Scenarios } & $\begin{array}{c}2048 \_ \\
\text {bytes }\end{array}$ & $\begin{array}{c}1024 \_ \\
\text {bytes }\end{array}$ & $\begin{array}{c}512 \_b \\
\text { ytes }\end{array}$ & $\begin{array}{c}256 \_b \\
\text { ytes }\end{array}$ & $\begin{array}{c}128 \_b \\
\text { ytes }\end{array}$ \\
\cline { 2 - 6 } 802.11 & 557.05 & 944.5 & $\begin{array}{c}1039 . \\
3\end{array}$ & $\begin{array}{c}1997 . \\
7\end{array}$ & $\begin{array}{c}3532 . \\
8\end{array}$ \\
\hline $802.11 g$ & 280.95 & 592.9 & 692.6 & $\begin{array}{c}1151 . \\
35\end{array}$ & $\begin{array}{c}2534 . \\
95\end{array}$ \\
\hline $\begin{array}{c}\text { TDMA+8 } \\
02.11\end{array}$ & 39.6 & 22.4 & 11.2 & 717.2 & 2572 \\
\hline $\begin{array}{c}\text { TDMA+8 } \\
02.11 \mathrm{~g}\end{array}$ & 3.2 & 3.6 & 0 & 0 & 2 \\
\hline
\end{tabular}




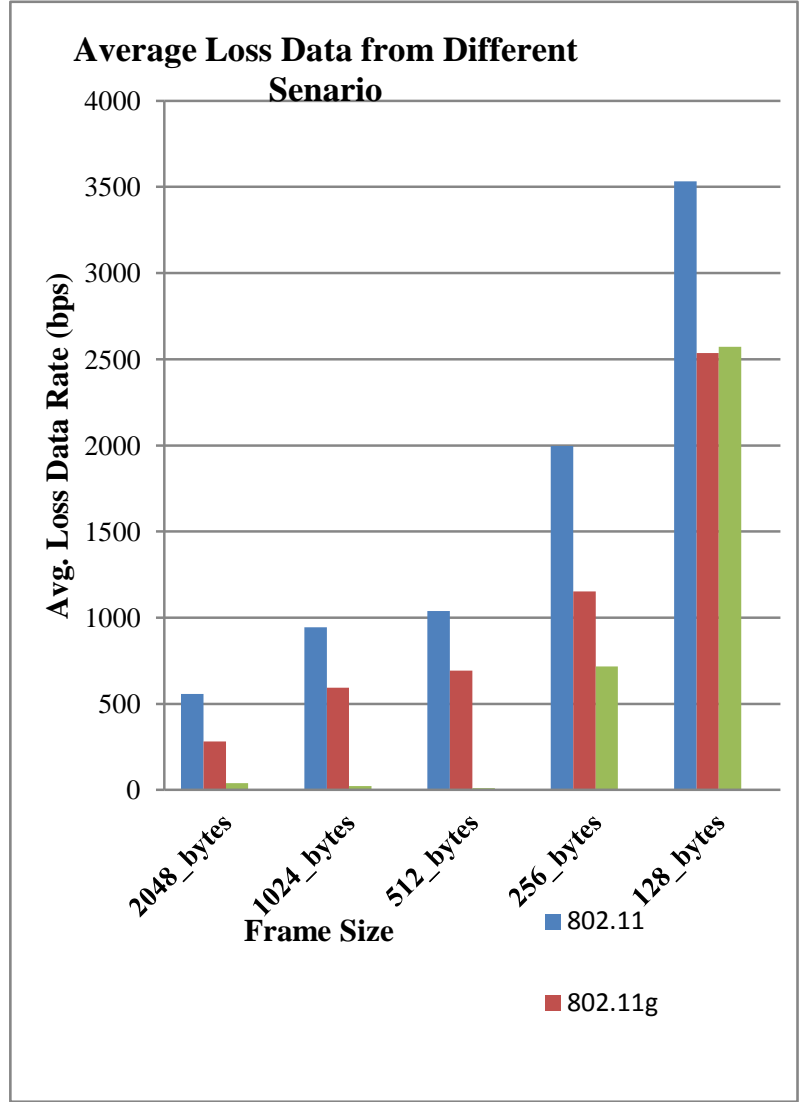

Fig. 4 Performance of average loss data rate vs. Packet size for Different scenario

\section{CONCLUSION}

In this simulation TDMA based approach implemented in MAC layer using NS-2 simulator. We are simulating different scenarios IEEE standards 802.11, 802.11g with TDMA and without TDMA approach. Our Simulation results are show in Fig. 3 and Fig. 4. Analysis the simulation result, performance improve in TDMA based approach as compare without TDMA approach, enhance the average receives data Rate and minimized the loss data. In future we find the large scale adhoc network, other performance parameters and also applied this technique in Wi-Max and Bluetooth scheme and analyze the results.

\section{REFERENCES}

[1] Pravin Ghosekar, Girish Katkar, Dr. Pradip Ghorpade "Mobile Ad-hoc Networks"IJCA Special Issue on MANETs,2010 page153-58.

[2] Omesh Tickoo and Biplab Sikdar, , "On the Impact of IEEE 802.11 MAC on Traffic Characteristics" IEEE JOURNAL ON SELECTED AREAS IN COMMUNICATIONS, VOL. 21, NO. 2, FEBRUARY 2003 p-189-203.

[3] B Naga Naveen, K Manikandan, "Novel approach for Improvisation of Medium Access Protocol for Wireless Sensors Networks "IJCSt Vol. 2, ISSue 2, June 2011, page 83-88.

[4] Gentian Jakllari, Ram Ramanathan, "A SYNC-LESS TIME-DIVIDED MAC PROTOCOL FOR MOBILE AD-HOC NETWORKS" 18-21 Oct. 2009 Military
Communications Conference, 2009. MILCOM 2009. Forman, G. 2003. An extensive empirical study of feature selection metrics for text classification. J. Mach. Learn. Res. 3 (Mar. 2003), 1289-1305.

[5] C. Umunna, F. Rabi, and A. Bah. "Application of TDMA technique to improve Data rate in Mobile ad hoc networks (MANET)" 11-10-2008.

http://lion.cs.uiuc.edu/ chunyuhu/publications/chunyuhu -UIUCDCS-R- 2005-2599-corr.pdf

[6] Jyh-Cheng Chen, Krishna M. Sivalingam, Prathima Agrawal, and Shalinee Kishore,"A Comparison of MAC Protocols forWireless Local Networks Based on Battery Power Consumption" AT\&T lab 1998.

http://reference.kfupm.edu.sa/content/c/o/a_comparison_ of_mac_protocols_for_wirele_369528.pdf

[7] MohammadReza EffatParvar, Peyman Teymoori, Nasser Yazdani, Ali Movaghar, Mehdi EffatParvar,"Evaluating Effectiveness of DSDV Routing Protocol on IEEE 802.11n Wireless LANs" International Journal of Electrical \& Computer Sciences IJECS-IJENS Vol: 10 No: 04 page 41-47.

[8] Narendran Rajagopalan and C. Mala,"MODIFIED POWER SAVE MODEL FOR BETTER ENERGY EFFICIENCY AND REDUCED PACKET LATENCY"American Journal of Engineering and Applied Sciences, 2012, 5 (3), 237-242.

[9] Yu Cheng, Xinhua Ling, Wei Song, Lin X. Cai, Weihua Zhuang and Xuemin Shen, "A Cross-Layer Approach for WLAN Voice Capacity Planning" IEEE JOURNAL ON SELECTED AREAS IN COMMUNICATIONS, VOL. 25, NO. 4, MAY 2007.

[10] Rashid saeed," system design and Implementation of TDMA-based wifi wireless network" International Arab journal of information technology, vol.9,No.02, march 2012.

[11] Wireless LAN Medium Access Control (MAC) and Physical Layer (PHY) Specifications, Amendment 8: Medium Access control (MAC) Quality of Service Enhancements, IEEE Std. 802.11e-2005 (November 2005).

[12] Wireless LAN Medium Access Control (MAC) and Physical Layer (PHY) Specifications, IEEE Std. 802.11, January 1997.

[13] S.Koteswararao, Dr.M.Sailaja, Dr.T.Madhu, P.Ramesh, V.Rajesh,"ENERGY AWARE TDMA MAC FOR WIRELESS SENSOR NETWORKS", International Journal of Distributed and Parallel Systems (IJDPS) Vol.2, No.5, September 2011.

[14] Seema Aarya,"Congestion Minimization through Collision Detection in TDMA and CSMA/CA Scheme in Wireless Mobile Ad-Hoc etwork",International Journal of Computer Applications (0975 - 8887) Volume 45No.1, May 2012.

[15] Rashid A. Saeed, Amran bin Hj Naemat, Azrin bin Aris Ir. Mat Khamis, " Evaluation of the IEEE 802.11p-based TDMA MAC method for Road Side-to-Vehicle Communications", Internation Journal of Network and Mobile Technologies, VOL 1/ISSUE 2/ NOVEMBER 2010. 
[16] M A Khan, T A Khan, M T Beg, "Performance Optimization of MAC Layer IEEE802.11 WLAN using Fragmentation" VSRD International Journal of Electrical, Electronics \& Communication Engineering", VSRD IJEECE, Dec 2012, pp 916-920

[17] T A Khan, M T Beg, M A Khan, "Evaluation of Back-off Algorithm performance of MAC layer IEEE 802.11WLAN" International Journal of Engineering and
Management Sciences, IJEMS, ISSN 2229-600x, April' 2013

[18] T A Khan, M T Beg, M A Khan, "Performance Analysis of WLAN using OPNET" International Journal of Innovative Technology and Exploring Engineering, IJITEE, Vol 2, Issue 5, April 2013, ISSN 2278-2375,PP $1-4$ 